\title{
DUKUNGAN KELUARGA MENGHADAPI KECEMASAN MENOPAUSE
}

\author{
Wiwin Renny Rahmawati \\ Poltekkes Kemenkes Semarang \\ email: wiwinrr@yahoo.co.id
}

\begin{abstract}
More women aged between 45-59 years experience a great deal of experiencing menopause. Anxiety occurs due to various reasons, one of which is the absence of family support.The purpose of this study was to determine the relationship between family support and anxiety in facing menopause in premenopausal mothers in Tidar Village, South Magelang. The research method used is cross sectional through data collection from 62 questionnaires distributed to 62 respondents. This study conducted an expert validity test with three experts. Univariate and bivariate data analysis. The statistical test used is the contingency coefficient test by including a $2 \times 2$ contingency table and using a significance level of 0.05. The results of statistical tests show the chi square value of 7.468 and a significance level of 0.006, this means that family support is needed for mothers who are facing premenopausal anxiety with a strong enough relationship. From this study it can be concluded that the existence of family support can reduce the anxiety experienced by premenopausal mothers when facing menopause. It is hoped that midwives can provide health education to families regarding the importance of family support for premenopausal mothers to reduce anxiety in mothers who are facing menopause.
\end{abstract}

Keywords: Family support; anxiety; menopause

\begin{abstract}
ABSTRAK
Wanita usia antara 45-59 tahun sebagian besar mengalami kecemasan menghadapi menopause. Kecemasan terjadi karena berbagai penyebab salah satunya yaitu tidak adanya dukungan keluarga dalam menghadapi menopause. Tujuan dilakukan penelitian ini adalah mengetahui hubungan antara dukungan keluarga degan kecemasan dalam menghadapi menopause pada ibu premenopause di kelurahan Tidar Magelang Selatan. Metode penelitian yang digunakan adalah cross sectional dengan total sampling. Penelitian ini melakukan uji validitas expert dengan tiga orang ahli. Analisa data secara univariat dan bivariat. Uji statistic yang digunakan adalah uji koefisien kontingensi dengan mencantumkan tabel kontingensi $2 \times 2$ dan menggunakan tingkat signifikansi 0,05 . Hasil uji statistic menunjukkan nilai chi kuadrat hitung 7,468 dan tingkat signifikansi 0,006, hal tersebut berarti bahwa dukungan keluarga diperlukan untuk ibu yang sedang menghadapi kecemasan premenopause dengan kekuatan hubungannya cukup kuat. Dari penelitian ini dapat ditarik kesimpulan bahwa adanya dukungan keluarga dapat mengurangi kecemasan yang dialami ibu premenopause saat menghadapi menopause. Saran untuk bidan diharapkan agar bisa memberikan pendidikan kesehatan kepada keluarga mengenai pentingnya dukungan keluarga pada ibu premenopause untuk mengurangi kecemasan pada ibu yang akan menghadapi menopause.
\end{abstract}

Kata Kunci: Dukungan Keluarga; Kecemasan; Menopause. 


\section{Pendahuluan}

Wanita umumnya mengalami gejala menopause dalam kehidupannya yang ditandai dengan berhentinya siklus menstruasi. Ini merupakan fase alamiah yang menandakan kesuburan wanita sudah berhenti. Seperti halnya menarche, hamil, nifas dan menyusui, menopause merupakan peristiwa yang sangat berarti bagi kehidupan wanita. Menarche menandakan dimulainya fase kesuburan wanita sedangkan menopause merupakan berakhirnya fase kesuburan.

Kondisi hormonal wanita yang mengalami menopause terjadi penurunan hormon-hormon reproduksi. Hormon yang menurun diantaranya adalah hormone estrogen. Penurunan hormone estrogen menyebabkan perubahan pada wanita yang mengalaminya. Penurunan hormone ini mengakibatkan perubahan fisik maupun psikis wanita. Pada usia subur, fluktuasi hormone ini menyebabkan gangguan stabilitas emosional wanita yang di kenal dengan pre mentruasi sindrom. Sedangkan pada fase menopause, secara fisiologis terjadi degenerasi dari organ organ reproduksi wanita hormone tidak mengalami fluktuasi seperti sebelumnya, tetapi menunjukkan grafik penurunan produksi. Secara fisik wanita yang menopause sudah tidak mengalami menstruasi lagi, selain tanda fisik tersebut wanita menopause juga mengalami gejala gangguan psikis.

Gejala gejala gangguan psikis yang dialami wanita menopause diantaranya adalah merasa khawatir terhadap hal-hal yang belum terjadi di masa mendatang, kecemasan dan ketakutan, berpikir terus menerus membayangkan hal hal yang tidak menyenangkan akan terjadi dan menimpa dirinya. Gejala awal menopause ini dikompensasi dengan kewaspadaan yang berlebihan sehingga wanita tersebut akan sulit untuk berkonsentrasi, mudah untuk beralih perhatian sampai mengalami gangguan pola istirahat dan tidur (Lestary, 2010).

Wanita yang berada Pada masa premenopause seringkali mengalami kecemasan karena persepsi yang timbul dari informasi yang diterimanya. Ada informasi yang benar tetapi adapula informasi yang bersifat mitos. Kecemasan- kecemasan ini berkaitan erat dengan beberapa faktor salah satunya adalah dukungan keluarga. Menurut Lestari (2010), keluarga merupakan organisasi maupun wadah yang mampu mempengaruhi dan memberikan dampak psikologis pada wanita menopause.

Menurut penelitian wanita yang mendapatkan dukungan keluarga mampu menghadapi masa-masa awal menopause dengan tenang. Memasuki menopause maka dukungan keluarga menjadi kebutuhan yang sangat penting untuk bisa mensuport atau memberikan rasa ketenteraman pada wanita. Dukungan keluarga dalam hal ini merupakan bantuan atau dukungan yang di terima wanita menopause dari orang-orang yang berada dalam lingkungan keluarga sehingga mereka akan merasa diperhatikan, dihargai dan dimengerti.

Hasil studi pendahuluan yang diperoleh penulis dari Kelurahan Tidar Magelang Selatan pada bulan Februari 2018 menunjukkan bahwa jumlah penduduk di Kelurahan Tidar pada bulan Februari 2018 sebanyak 7926 jiwa yang tebagi menjadi penduduk laki-laki 3951 jiwa yang wanita ada 3975 jiwa. Jumlah penduduk wanita usia 45-49 tahun sebanyak 289 orang yang didapat dari $10 \mathrm{RW}$ di Kelurahan Tidar. Dari penduduk wanita di usia tersebut didapatkan bahwa sebagian wanita premenopause mengalami kecemasan menghadapi menopause, salah satu sebabnya adalah karena tidak adanya dukungan keluarga terhadap mereka menghadapi masa-masa menjelang menopause.

Berdasarkan latar belakang masih adanya angka kecemasan pada wanita premenopause menghadapi menopause yang salah satunya dikarenakan tidak adanya dukungan keluarga di Kelurahan Tidar Untuk itu perlu dilakukan penelitian tentang hubungan dukungan keluarga dan kecemasan pada ibu premenopuase dalam menghadapi menopause di Kelurahan Tidar Magelang Selatan Tahun 2018".

Tujuan umum dari penelitian ini adalah untuk mengetahui dukungan keluarga dan hubungannya dengan kecemasan pada ibu premenopuase dalam menghadapi menopause di Kelurahan Tidar Magelang Selatan. 


\section{Metode Penelitian}

Desain penelitian yang digunakan adalah analitik korelasi yang berusaha untuk membuktikan apakah ada hubungan dukungan keluarga terhadap kecemasan menghadapi menopause pada ibu premenopause. Pendekatan waktu yang digunakan adalah cross sectional yaitu suatu penelitian untuk mempelajari dinamika korelasi antara faktor-faktor resiko (dukungan keluarga) dengan efek (kecemasan), dengan cara pendekatan, observasi atau pengumpulan data sekaligus pada suatu saat (point of approach), artinya, tiap subjek penelitian hanya diobservasi sekali saja dan pengukuran dilakukan terhadap status karakter atau variabel subjek pada saat pemeriksaan (Notoatmodjo, 2005). Dalam penelitian ini mengkaji ada/tidaknya dukungan keluarga, apabila ada, apakah dukungan keluarga berhubungan dengan kecemasan dalam menghadapi menopause pada ibu premenopause.

Populasi penelitian adalah wanita premenopause (usia 45-50 tahun) yang tinggal serumah dengan suami dan anaknya di Kelurahan Tidar Magelang Selatan yang berjumlah 62 tersebar di 10 RW diambil dari data sekunder yaitu data penduduk bulan Februari 2018. Teknik sampling yang digunakan adalah total sampling.

\section{Hasil dan Pembahasan}

Hasil penelitian ini disajikan dalam dua jenis analisis yaitu analisis univariat dan analisi bivariat. Analisis univariat digunakan untuk mengetahui distribusi frekuensi dukungan keluarga pada ibu premenopause dan kecemasan menghadapi menopause. Sedangkan analisis bivariat digunakan untuk mengetahui hubungan antara dukungan keluarga dengan kecemasan menghadapi menopause pada ibu premenopause.

Berdasarkan definisi operasional yang ditetapkan, bahwa untuk parameter dukungan keluarga parsial atau dukungan keluarga penuh menggunakan nilai mean. Berdasarkan pengolahan data dengan Microsoft Excel, diperoleh mean dari kuesioner dukungan keluarga adalah 17,05, jadi jika jumlah jawaban responden dalam menjawab "Ya" $\leq 17$ maka dukungan keluarga masuk dalam dukungan keluarga parsial dan jika jawaban "Ya" $\geq 17$ maka dukungan keluarga masuk kategori dukungan keluarga penuhpenuh.

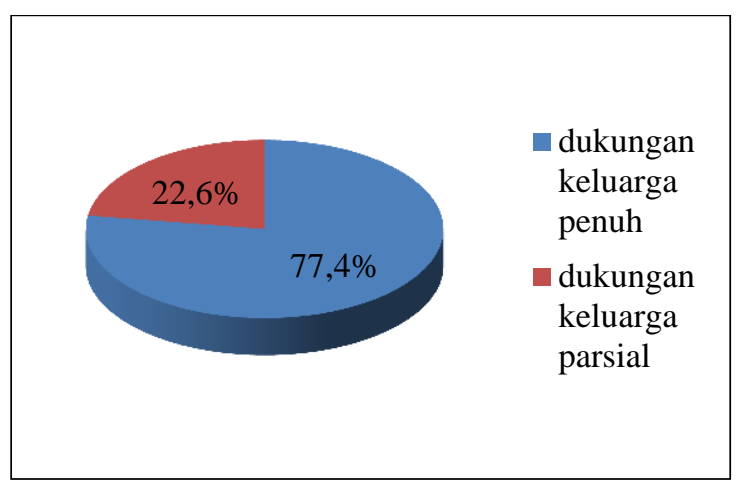

Gambar 1: Frekuensi Dukungan keluarga pada Ibu Premenopause di Kelurahan Tidar Magelang Selatan

Dukungan keluarga dalam penelitian ini dapat lihat pada Gambar 1, bahwa sebagian besar ibu menopause mendapatkan dukungan penuh dari keluarga, yaitu $77,4 \%$ atau 48 responden, sedangkan $22,6 \%$ atau 14 responden mendapatkan dukungan keluarga yang parsial.

Parameter yang digunakan untuk mengukur kecemasan mengahadapi menopause pada ibu premenopause adalah dengan kuesioner Taylor Manifest Anxiety Scale (T-MAS) yang sudah di modifikasi oleh peneliti sesuai definisi operasional yang sudah dijelaskan pada bab tiga. Jika jawaban "Ya" $\leq 11$ berarti tidak mengalami kecemasan dan jika jawaban "Ya" $\geq 12$ berarti mengalami kecemasan. Hasil pentabulasian data didapatkan bahwa sebanyak $66,1 \%$ atau 41 responden tidak mengalami kecemasan dalam menghadapi menopause, sedangkan $33,9 \%$ atau 21 orang responden mengalami kecemasan menghadapi menopause. Distribusi frekuensi kecemasan responden dalam menghadapi menopause ditampilkan dalam diagram pada gambar 2 . 


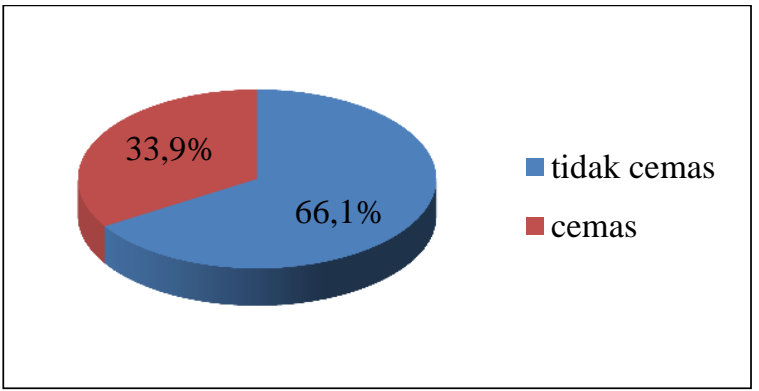

Gambar 2: Distribusi Frekuensi Kecemasan Menghadapi Menopause di Kelurahan Tidar Magelang Selatan

Hubungan antara dukungan keluarga
dengan kecemasan menghadap menopause pada ibu premenapause di Kelurahan Tidar Magelang Selatan dapat dilihat pada table 1. Dapat dilihat dari hasil uji statistic nilai chi kuadrat hitung dan hasil signifikasinya yang dihasilkan, dengan ketentuan bahwa kedua variabel yang diuji mempunyai hubungan jika signifikansi < 0,05 dan nilai chi kuadrat hitung lebuh besar dari chi kuadrat tabel. Berdasarkan hasil analisis dapat diketahui bahwa signifikansi chi kuadrat yang dihasilkan sebesar 0,006 $(\mathrm{p}<0,05)$ dan hasil $\mathrm{X}^{2}=$ 7,468 lebih besar dari $X^{2}$ tabel yaitu 3,841 . Dengan demikian ada hubungan antara dukungan keluarga dengan kecemasan menghadapi menopause pada ibu premenopause di Kelurahan Tidar Magelang Selatan, dengan demikian hasil uji hipotesa ini menunjukkan bermakna secara statistik. Sedangkan apabila dilihat dari nilai koefesien kontingensi $(0,328)$, maka hubungan ini mempunyai hubungan yang cukup kuat.

Tabel 1. Tabulasi Silang Dukungan Keluarga dan Kecemasan lbu Premenopause di Kelurahan Tidar Magelang Selatan

\begin{tabular}{llll}
\hline \multicolumn{4}{c}{ Kecemasan } \\
\hline & Cemas & $\begin{array}{l}\text { Tidak } \\
\text { Cemas }\end{array}$ \\
\hline Dukungan & 9 & 5 & 14 \\
parsial & $64,3 \%$ & $37,7 \%$ & $100 \%$ \\
\hline Dukungan & 12 & 36 & 48 \\
Penuh & $25 \%$ & $75 \%$ & $100 \%$ \\
\hline$P=0,006$ & $x^{2}=7,468$ & $\mathrm{C}=0,328$ & \\
\hline
\end{tabular}

Berkurangnya kecemasan ibu dalam menghadapi menopause adalah keadaan yang diharapkan ibu dan keluarga, karena dapat memperlancar pelaksanaan kegiatan harian. Kecemasan ibu dalam menghadapi premenopause dapat diantisipasi dengan tindakan keluarga yaitu dengan pemberian support mental dari keluarga. Keberhasilan pelaksanaan support mental tergantung dari kemampuan keluarga dalam melaksanakannya. Selain dipengaruhi oleh tingkat pengetahuan keluarga, Perilaku keluarga kemungkinan dipengaruhi pula oleh tersedianya faktor- faktor pendukung seperti fasilitas-fasilitas atau sarana kesehatan yang dibutuhkan.

$$
\text { Dukungan keluarga sangat }
$$

dibutuhkan ibu dalam menghadapi premenopause, dengan dukungan keluarga maka kecemasan yang dialami oleh ibu akan berkurang. Bentuk dukungan yang dapat diberikan keluarga dalam mengurangi kecemasan ibu ini dapat dilakukan dengan beberapa cara lain: Keluarga peduli dengan masalah yang ibu hadapi, keluarga mengajak membicarakan masalah yang sedang dihadapi, keluarga memberikan saran agar ibu lebih menjaga kesehatan, Suami tidak mempermasalahkan fisik pasangannya yang sudah tidak sebaik pada masa subur, serta keluarga menerima kondisi ibu yang tidak sekuat dan selincah dulu. Selain lingkungan sosial, dukungan keluarga dapat mengurangi efek dari kecemasan menopause (Lestary, 2010).

Terdapat hubungan yang bermakna antara dukungan keluarga dengan kecemasan yang dialami seorang wanita dalam menghadapi menopause. Hubungan antar dukungan keluarga dengan kecemasan ibu dalam menghadapi menopause menunjukkan arah hubungan berbanding terbalik atau negatif artinya, semakin banyak dukungan yang diberikan oleh keluarga, maka tingkat kecemasan ibu juga akan semakin menurun atau semakin tidak ada. Sebaliknya semakin kecil perhatian dan dukungan yang diberikan keluarga akan membuat tingginya tingkat kecemasan ibu dalam menghadapi menopause. 


\section{Kesimpulan}

Setelah dilakukan analisa data dari data tersebut, maka dapat ditarik hipotesa "Ada hubungan antara dukungan keluarga dengan kecemasan menghadapi menopause pada ibu premenapause di Kelurahan Tidar Magelang Selatan" dengan signifikansi $0,006(\mathrm{p}<0,05)$ dan $\mathrm{x}^{2}$ hitung $=$ 7,468 ( lebih dari chi kuadrat tabel $=3,841$ ). Dan nilai koefisien kontingensi 0,328 , sehingga hubungan ini mempunyai hubungan cukup kuat.

Dengan hasil penelitian ini, mengingat pentingnya peran serta keluarga dalam mengurangi kecemasan ibu dalam menghadapi menopause, maka diperlukan usaha-usaha memberikan pendidikan kesehatan kepada keluarga melalui kegiatan kemasyarakatan untuk meningkatkan kesehatan lbu dan anak khususnya ibu yang memasuki masa menopause dengan cara memberikan penyuluhan pada keluarga sehingga keluarga dapat memberikan dukungan yang tepat untuk mengurangi kecemasan ibu..

\section{Ucapan Terima Kasih}

Ucapan terima kasih kami sampaikan kepada Kepala Dinas Kesehatan Kota Magelang dan jajarannya yang telah memberikan ijin dalam pelaksanaan penelitian.

\section{Daftar Pustaka}

Akhmadi. (2009). http://www.rajawana.com/artikel/keseh atan/435 - dukungan - keluarga. Html. Tanggal 25 Februari 2018

Baziad, Ali. (2003). Menopause Dan Andropause. Jakarta : Yayasan Bina Pustaka Sarwono Prawirohardjo

Hawari, Dadang. (2009). Psikometri Alat Ukur (Skala) Kesehatan Jiwa. Jakarta : FKUI

Hidayat, A. (2007). Metode Penelitian Kebidanan dan Teknik Analisa Data. Jakarta : Salemba Medika

Kasdu, Dini. (2002). Kiat Sehat Dan Bahagia di Usia Menopause. Jakarta : Puspa Swara
Komalasari, Renata dkk. (2008). Buku Ajar Keperawatan Jiwa. Jakarta : EGC

Lestary, Dwi. (2010). Seluk Beluk Menopause. Yogyakarta : Garailmu

Maryam, R Siti dkk. (2008). Mengenal Usia Lanjut dan Perawatannya. Jakarta : Salemba medika

Mitrariset. (2008). Kecemasan atau Ansietas. http ://www.mitrariset.com/2008/II/Kecemas an-atau-ansietas. Html. Tanggal 25 Februari 2018

Noorkasiani dan S.Tamher. (2009). Kesehatan Usia Lanjut dengan Pendekatan Asuhan Keperawatan. Jakarta : Salemba Medika

Notoatmodjo, Soekidjo. (2005). Metodologi Penelitian Kesehatan. Jakarta : Rineka Cipta

Nursalam. (2009). Konsep dan Penerapan Metodologi Penelitian IImu Keperawatan. Jakarta : Salemba Medika

Prawirohusodo, S. (2000). Stress dan Kecemasan : Simposium Stres dan kecemasan. Laboratorium Kedokteran Jiwa. FK UGM : Yogyakarta

Proverawati, a dan Sulistyawati, E. (2010). Menopause dan Sindrom Premenopause. Yogyakarta : Nuha Medika

Purnami, C.T. 2004. Aplikasi SPSS Versi 10 Untuk Pengelolaan Data. Semarang : UNDIP

Santrock John W. (2002). Life-Span Development ( Perkembangan Masa Hidup ). Jakarta : Gelora Aksara Pratama

Sibagariang Eva Ellya, dkk. (2010). Kesehatan Reproduksi Wanita. Jakarta: Trans Info Media

Stuart, Gail W. (2006). Buku Saku Keperawatan Jiwa. Jakarta : EGC

Suprajitno, S.Kp. (2004). Asuhan Keperawatan Keluarga. Jakarta : EGC

Wirakusumah, Emma S. (2003). Tips \& Solusi Gizi Untuk Tetap Sehat Cantik dan Bahagia di Masa Menopause dengan Terapi Estrogen Alami. Jakarta: Gramedia Pustaka Utama 